\section{Análise bioética acerca do "Termo de Consentimento e Responsabilidade para Profilaxia Primária em Hemofilia"}

\section{Gois, Andrea Carolina Lins de}

Programa de Pós-Graduação em Bioética da Cátedra UNESCO da Universidade de Brasília. Contato e-mail: andreaclgois@gmail.com

\section{Melo, Kleber Pessoa de}

Programa de Pós-Graduação em Bioética da Cátedra UNESCO da Universidade de Brasília.

\section{Lima, Meiriany Arruda \\ Programa de Pós-Graduação em Bioética da Cátedra UNESCO da Universidade de Brasília.}

PALAVRAS-CHAVE: Adolescente, Hemofilia, Capacidade, Autonomia, TCLE.

INTRODUÇÃO: este produto tem como objetivo uma análise bioética acerca do "Termo de Consentimento e Responsabilidade para Profilaxia Primária em Hemofilia”, com intuito de indicar melhorias e sugestões éticas, de modo a fortalecer a autonomia e o respeito à capacidade das crianças e dos adolescentes hemofílicos e seus familiares frente às adversidades enfrentadas na lida diária com a doença. Para tanto, faz-se necessária a análise acerca da importância do Termo de Assentimento - TA, bem como, do Termo de Consentimento Livre e Esclarecido - TCLE. Enquanto o primeiro deve fornecer informações a respeito do estudo, em linguagem clara, incluindo objetivos, métodos, benefícios, riscos, para que o próprio paciente/adolescente conceda a sua anuência, o segundo esta voltado para o TCLE, este deverá ser assinado pelos responsáveis legais do paciente/adolescente, atualmente indispensável para validação do TA, o TCLE contém informações necessárias, para que eles expressem a sua concordância. MÉTODO: trata-se de uma pesquisa qualitativa descritiva a partir da análise documental, revisão bibliográfica e legislativa realizada através das bases de dados de domínio público, tais como Scielo, Pub Med, LILACS, bem como, do TCLE e TA elaborados pela Secretária de Saúde do Distrito Federal entregue aos pacientes e seus responsáveis legais, quando aplicáveis, para o tratamento da hemofilia. RESULTADOS: existem indagações que questionam a partir de qual momento pode-se considerar a criança e o adolescente enquanto indivíduo autônomo e em quais casos eles poderiam tomar decisões por si próprios. Para a adequada compreensão dos participantes, o TA deve, portanto, conter uma linguagem adequada às diferentes faixas etárias. O TA é um dos documentos mais importantes para apreciação ética que envolvem crianças e adolescentes, pois, por meio dele, os participantes menores exercem seu direito de autonomia, de escolherem participar ou não de um tratamento, após serem devidamente esclarecidos. Para que seja pleno, o assentimento deve ser obtido através de uma decisão voluntária dos participantes, baseado em informações claras, com linguagens acessíveis às idades do público alvo, pois o objetivo do TA é dar fundamentos para a decisão dos participantes. CONCLUSÃO: verifica-se que há uma grande distância entre o que se mostra ideal quanto à prática do TA e do TCLE em relação ao que se tem ofertado aos pacientes hemofílicos do DF, por meio do "Termo de Consentimento e Responsabilidade para Profilaxia Primária em Hemofilia". Para indicação de melhorias e sugestões, com parâmetros bioéticos, busca-se na Ética das Virtudes, de Aristóteles, a necessária equidade ("fairness") e no cuidado centrado no paciente, a base norteadora desta análise, de forma a amparar os pacientes, notoriamente tratados como mais desfavorecidos, de forma a serem vistos e reconhecidos como também merecedores de importância social.

AGRADECIMENTOS: ao corpo docente e aos coordenadores professores Doutor Volnei Garrafa e professor Doutor Natan Monsores da Cátedra UNESCO de Bioética da Universidade de Brasília - UnB.

\section{REFERÊNCIAS:}

[1] W. Maradola, M. F. T. Maradola, F. F. Castaldeli, M. Falci, GIT, Anais (2004).

[2] Protocolo Integral às Pessoas com Hemofilias A e B, 47 (2017).

[3] Brasília, Ministério da Saúde, Normas e Manuais Técnicos. 68 (2011).

[4] M. E. Jager, J. Gonçalves, A. C. G. Dias, C. L. C. Beck, Psi. Rev. 5, 5,134-149 (2013).

[5] World Health Organization. Informed Consent Form Templates - Informed Assent Form Template for Children/Minors, Disponível: http://www.who.int/rpc/research_ethics/informed_consent/en 